2014-03-21

\title{
Monodialectal and multidialectal infants' representation of familiar words
}

\author{
Durrant, S
}

http://hdl.handle.net/10026.1/3379

10.1017/S0305000914000063

Journal of Child Language

Cambridge University Press

All content in PEARL is protected by copyright law. Author manuscripts are made available in accordance with publisher policies. Please cite only the published version using the details provided on the item record or document. In the absence of an open licence (e.g. Creative Commons), permissions for further reuse of content should be sought from the publisher or author. 


\section{Journal of Child Language}

http://journals.cambridge.org/JCL

Additional services for Journal of Child

Language:

Email alerts: $\underline{\text { Click here }}$

Subscriptions: Click here

Commercial reprints: $\underline{\text { Click here }}$

Terms of use : $\underline{\text { Click here }}$

\section{Monodialectal and multidialectal infants' representation of familiar words}

SAMANTHA DURRANT, CLAIRE DELLE LUCHE, ALLEGRA CATTANI and CAROLINE FLOCCIA

Journal of Child Language / FirstView Article / March 2014, pp 1 - 19

DOI: 10.1017/S0305000914000063, Published online: 21 March 2014

Link to this article: http://journals.cambridge.org/abstract S0305000914000063

How to cite this article:

SAMANTHA DURRANT, CLAIRE DELLE LUCHE, ALLEGRA CATTANI and CAROLINE FLOCCIA Monodialectal and multidialectal infants' representation of familiar words . Journal of Child Language, Available on CJO 2014 doi:10.1017/ S0305000914000063

Request Permissions : $\underline{\text { Click here }}$ 


\title{
Monodialectal and multidialectal infants' representation of familiar words*
}

\author{
SAMANTHA DURRANT, CLAIRE DELLE LUCHE, \\ ALLEGRA CATTANI AND CAROLINE FLOCCIA \\ School of Psychology, Plymouth University, $U K$
}

(Received 2 I November 20I2-Revised 30 fuly 2013-Accepted 20 Fanuary 2014)

\begin{abstract}
Monolingual infants are typically studied as a homogenous group and compared to bilingual infants. This study looks further into two subgroups of monolingual infants, monodialectal and multidialectal, to identify the effects of dialect-related variation on the phonological representation of words. Using an Intermodal Preferential Looking task, the detection of mispronunciations in familiar words was compared in infants aged $\mathrm{I} ; 8$ exposed to consistent (monodialectal) or variable (multidialectal) pronunciations of words in their daily input. Only monodialectal infants detected the mispronunciations whereas multidialectal infants looked longer at the target following naming whether the label was correctly produced or not. This suggests that variable phonological input in the form of dialect variation impacts the degree of specificity of lexical representations in early infancy.
\end{abstract}

\section{INTRODUCTION}

Language development research traditionally relies on the dichotomy between two distinct populations: monolinguals and multilinguals (e.g. Bosch \& Sebastián-Gallés, 2003; Fennell, Byers-Heinlein \& Werker, 2007; Ramon-Casas \& Bosch, 2010). However, these broad categories cannot provide a completely accurate description of infants' language input. Monolingual infants actually fall into one of two subgroups: monodialectal or multidialectal. Multidialectal infants hear multiple dialects of a single native language if one or both of their parents speak with a

[*] This work was supported by grants from the Nuffield Foundation (2008-20I I) and the ESRC (2009-20I I) awarded to the last author. Special thanks are also due to all the toddlers and their parents who participated in this study. Address for correspondence: Samantha Durrant, School of Psychology, Plymouth University, Drake Circus, PL4 8AA, Plymouth, UK. tel: +44 I752584859; e-mail: samantha.durrant@plymouth.ac.uk 
dialect that differs from the surrounding locality. Albareda-Castellot, Pons, and Sebastian-Galles (20II) suggest that multidialectal infants be seen as a unique group of bilinguals, acquiring a single set of morphological and syntactic rules but two distinct phonologies (to varying degrees) with a large proportion of cognates in their lexicon. Of interest in the current study is how life-long exposure to dialectal variation affects infants' representations of familiar words.

In many ways the general pattern of language development in bilingual and monolingual infants is comparable, with all infants passing critical milestones at similar ages (Pearson, Fernández \& Oller, I 993). However, when looking at vocabulary scores, differences have been identified between monolingual and bilingual populations (Bialystok, Luk, Peets \& Yang, 20I0). Typically, bilingual infants have fewer words in their vocabulary than monolingual peers when considering each of their languages; however, when collapsing all words across both languages, bilingual infants' scores are comparable to those of monolinguals (Poulin-Dubois, Bialystok, Blaye, Polonia \& Yott, 2013).

Differences also seem to arise between these two populations when exploring the specificity of their word representations. Bilingual infants seem to detect minimal changes between words later than their monolingual peers. Using a Switch task (Werker, Cohen, Lloyd, Casasola \& Stager, I 998), Fennell et al. (2007) taught infants the novel word-object pairings 'bih' and 'dih' and then tested them on trials where these pairings were congruent with training or where there was a mismatch or 'switch' between the label and the object. Monolingual infants succeed at noticing the switch at age $\mathrm{I} ; 5$, whereas bilingual infants are successful only at $\mathrm{i} ; 8$. This suggests that bilingual infants have less specific representations of words than their monolingual counterparts (see also Bosch \& Sebastián-Gallés, 2003). Following the suggestion from Albareda-Castellot et al. (20 I I) that multidialectalism is a unique form of bilingualism, we propose that multidialectal infants might behave more similarly to bilingual infants than monolingual monodialectal infants.

It has been shown that increased variability in speech can affect performance in monolingual infants. For example, Rost and McMurray (2009) trained infants aged $\mathbf{I} ; 2$ in a Switch task with minimal pair words /buk/and /puk/, with training sequences produced by either single or multiple speakers. Infants only looked longer during switch trials following the multiple speaker training phase, suggesting that speaker-related variability leads infants to focus on the stable or invariant aspects of the input and develop more robust representations of words. In a follow-up study, Rost and McMurray (2010) manipulated phonetic variability more closely in the same task with the same stimuli. When varying cues that are either phonetically contrastive (VOT) or non-contrastive (prosodic and indexical), they found that infants 
only noticed the switch when the non-contrastive cues were present, failing to look longer to switch trials with contrastive cues alone. In contrast, when phonetic information remained consistent but non-contrastive cues varied, infants once again succeeded. This suggests that phonetically contrastive variability can be problematic for creating phonologically specific representations of new words. However non-contrastive variability, such as speaker differences that are usually not used to discriminate words, can support learning. Multidialectal infants are exposed regularly to phonetically contrastive cues that are not phonologically relevant (such as rhotic versus non-rhotic pronunciations of final tense vowels as in car). Following Rost and McMurray (2010), we would predict that multidialectal infants' exposure to phonetically variable tokens of words may result in less well defined representations being incorporated into their lexicon.

However, the study of the impact of dialectal variations on infants' word representations has led to mixed conclusions so far. Best, Tyler, Gooding, Orlando \& Quann (2009) played American infants familiar words in either a Jamaican (unfamiliar) or American-English (familiar) accent in a Headturn Preference Procedure (HPP). At I;3, infants listened longer to familiar words in a familiar accent over an unfamiliar one, whereas at $\mathrm{I} ; 7$ listening times were comparable for both accents. That is, until $1 ; 7$ infants failed to recognize familiar words produced with unfamiliar pronunciations due to accent differences. This indicates that unfamiliar within-language variation can negatively affect word recognition (see also Schmale, Cristia, Seidl \& Johnson, 2010).

Alternatively, Schmale, Hollich and Seidl (201 I) present evidence that accent-related variability can aid the creation of robust representations of words. Infants aged 2;0 were trained on novel words in either a foreign or local accent and tested in the reverse using a variant of the Intermodal Preferential Looking procedure (IPL; Bailey \& Plunkett, 2002). Infants looked longer to the target only when training was in the foreign accent; training in the local accent resulted in no preference for the target. Schmale et al. (201 I, p. I I05) suggest that "exposure to phonetic variability leads to more robust representations by promoting broader lexical categories". In the foreign accent training condition word representations better accommodated variation, whereas training in a familiar local accent made abstraction across similar instances more difficult in young infants.

In an attempt to explore this further, White and Aslin (201 I) trained infants with mispronunciations of familiar words containing the shifted vowel [p] to [æ], e.g. $d o g$ to $d a g$, prior to testing. Infants were tested with both correct and incorrect pronunciations of familiar words in a typical IPL task, with incorrect pronunciations using the trained vowel shift. They found that following brief exposure to a novel accent, infants aged I;8 could accommodate this shift and recognize incorrect pronunciations 
of familiar words, as only infants who were trained looked longer to the target following the mispronunciation. Additionally, the successful infants recognized mispronounced words they had not previously heard, showing generalization of the shift to other exemplars. So, with relevant exposure to accent variations (in this case an artificial novel accent), infants are able to accommodate incorrect pronunciations of familiar words.

The above studies demonstrate infants' ability to adapt rapidly at the time of testing to deviant pronunciations of words, both familiar and novel. However, multidialectal infants are faced with within-language variation on a daily basis due to the nature of their input, and so present an interesting case for study and for comparison with the traditional bilingual/monolingual contrast. Here, we examined the impact of continuous naturalistic dialect-related variability on infants' phonological representations of familiar words, rather than an introduced and specifically designed variability as in Best et al. (2009), Schmale et al. (2011), and White and Aslin (201 I). Using a standard IPL procedure we tested monodialectal and multidialectal infants on correct and incorrect pronunciations of familiar words produced in the local British South West English dialect.

We predicted that our monodialectal group of infants would behave as expected from the previous literature when monolinguals are presented with mispronunciations of familiar words (Mani \& Plunkett, 2010; Swingley \& Aslin, 2000): they should only look longer at the target following correct pronunciations. However, multidialectal infants could respond in one of two ways. First, they could detect mispronunciations similarly to or better than monodialectals, looking longer to the target following correct but not incorrect pronunciations. This would suggest that they have representations that are sufficiently specified that deviant pronunciations are successfully identified. It could also suggest that any relaxation or broadening of phonetic boundaries is input-specific, and does not apply to any presented phonetic or phonemic contrast as expected following studies by Schmale et al. (20II) and White and Aslin (20II). Due to the design of this study these two explanations would be difficult to disentangle at this stage. Second, infants could treat all pronunciations as acceptable exemplars of the target and look longer at its picture regardless of pronunciation, suggesting a general relaxation or broadening of phonetic boundaries or poorer use of phonological information in word recognition, as a result of daily exposure to variable pronunciations, as suggested by results from Best et al. (2009) and Rost and McMurray (2010).

\section{METHOD}

English-learning toddlers aged $\mathrm{I} ; 8$ were presented with pairs of images accompanied by correct or incorrect pronunciations of a target. Sensitivity 
to mispronunciations of familiar words should result in longer looks to the target image following correctly but not incorrectly pronounced trials as compared to the prenaming phase (e.g. Mani \& Plunkett, 2007).

\section{Participants}

Thirty-two monolingual English infants born and raised in the South West of England successfully completed this study. There were two groups of infants: monodialectals $\left(N={ }_{1} 6,5\right.$ boys, mean age $\left.=_{1} ; 7 \cdot 25\right)$ and multidialectals $\left(N=\mathrm{I} 6\right.$, I2 boys, mean age $\left.=_{\mathrm{I}} ; 8 \cdot 02\right)$. Additional infants were tested but excluded due to inattention (3) and fussiness (2). All infants had no known hearing problems, developmental delays, were no more than six weeks premature, and were recruited from the Babylab database. All parents completed the Oxford Communicative Development Inventory (OCDI; Hamilton, Plunkett \& Schafer, 2000) with no significant difference found between the two groups (mean understanding scores - monodialectals $=235$ words, range $33-348$; and multidialectals $=23 \mathrm{I}$ words, range $\mathrm{I} 40-354$, $t(30)=-0.15, p=.88$; mean production scores - monodialectal $=79$ words, range $=\mathrm{I} 2-\mathrm{I} 80$ and multidialectal $=9 \mathrm{I}$ words, range $=7-240, t(30)=0.57$, $p=\cdot 57)$. Infants were classified as mono- or multidialectal prior to testing. Parents reported their dialect background and were recorded reading an elicitation passage (Weinberger, 2003; see 'Appendix A') in addition to some natural speech describing a typical day with their child. Expert listeners, familiar with the English South West dialect, assessed these recordings in order to determine whether the speaker spoke with a South West accent or not. Given the suggestion from Trudgill (I999) that the major dialect boundary of British English lies between the North and South and the specification from Altendorf and Watt (2004) that the South of England is further separated into three dialect areas: South West, East Anglia and South East, infants whose parents both spoke with a South West dialect were classified as monodialectal (See 'Appendix B' for details of the most common differences between the dialects heard by infants tested and that of the South West of England). All other infants were considered multidialectal (see 'Appendix C' for a full list, including percentage of exposure to the South West dialect).

A dialect exposure questionnaire was completed, derived from a language exposure questionnaire (Cattani et al., in press; see 'Appendix D') calculating the amount of exposure to the South West dialect. Multidialectal infants' exposure scores were required to be between 25 and $75 \%$ to be included in this group, following the bilingual literature (Pearson, Fernández, Lewedeg \& Oller, I997). On average, multidialectals heard the local dialect $42 \%$ of the time (range $26 \%$ to $69 \%$ ). Dialect status 
TABLE I . Summary of stimuli and phonetic transcriptions used for correct and incorrect trials. Percentages represent the number of infants aged $I ; 8$ who know the target and distracter words based on OCDI norms (Hamilton et al., 2000)

\begin{tabular}{|c|c|c|c|}
\hline Target & $\begin{array}{l}\text { Consonant } \\
\text { mispronunciation }\end{array}$ & $\begin{array}{l}\text { Vowel } \\
\text { mispronunciation }\end{array}$ & Distracter \\
\hline Ball (го०\%) /bo:l/ & /gว:1/ & /bu:1/ & Bear $(86 \%)$ \\
\hline Bath $(93 \%) / \mathrm{ba}: \theta /$ & /da: $\theta /$ & $/ \mathrm{b} \varepsilon \theta /$ & Boat $(64 \%)$ \\
\hline $\operatorname{Bed}(100 \%) / \mathrm{bed} /$ & $/ \mathrm{p} \varepsilon \mathrm{d} /$ & $/ \mathrm{b} \Lambda \mathrm{d} /$ & Book $(93 \%)$ \\
\hline $\operatorname{Bib}(79 \%) / \mathrm{bib} /$ & /dib/ & /bæb/ & Boot $(79 \%)$ \\
\hline Bread $(86 \%) / \mathrm{bred} /$ & /gred/ & /bro:d/ & Brush $(100 \%)$ \\
\hline Bus $(79 \%) / \mathrm{b} \Lambda \mathrm{s} /$ & /pas/ & /bæs/ & Bike $(93 \%)$ \\
\hline Cat (I00\%)/kæt/ & /gæt/ & /ka:t/ & Cow $(93 \%)$ \\
\hline $\operatorname{Cot}(\mathrm{I} 00 \%) / \mathrm{kpt} /$ & /tnt/ & /ket/ & Car (I00\%) \\
\hline Cup (7I\%) /kıp/ & $/ \mathrm{g}_{\Lambda} \mathrm{p} /$ & /kep / & Clock $(86 \%)$ \\
\hline $\operatorname{Dog}(\mathrm{I} \circ 0 \%) / \mathrm{dpg} /$ & /bog/ & /dug/ & Duck (I00\%) \\
\hline Foot (71\%)/fut/ & /sut/ & /fo:t/ & Fish $(7 \mathrm{I} \%)$ \\
\hline Hat $(86 \%) / h æ t /$ & $/ \int æ t /$ & /het/ & Horse $(93 \%)$ \\
\hline Keys $(86 \%) / \mathrm{ki}: \mathrm{z} /$ & $\mid \mathrm{ti}: \mathrm{z} /$ & /kæz/ & Coat $(79 \%)$ \\
\hline Shoe (го०\%) / /u:/ & /fu:/ & //ii:/ & Shop (7 I \%) \\
\hline Sock $(\mathrm{I} 00 \%) / \mathrm{sbk} /$ & /zok/ & /suk/ & Spoon $(79 \%)$ \\
\hline Tree $(64 \%) /$ tri:/ & /pri:/ & /tru:/ & Train $(7 \mathrm{I} \%)$ \\
\hline
\end{tabular}

was obtained prior to testing to ensure that each group contained all of the possible trial combinations; coders were naive to this information.

\section{Stimuli}

Thirty-two monosyllabic consonant-initial nouns were selected from the OCDI as understood by children at this age (see Table I). These were divided into sixteen target (mean understanding score $=88 \%$ ) and distracter $(84 \%)$ pairs. Each infant saw all sixteen pairs once, with one image acting as the target for all infants, e.g. target $d o g$ and distracter $d u c k$. The images were all colour photographs, controlled for size, and appeared on a white background. They were deemed good exemplars by the authors and an independent observer. Infants saw sixteen trials including eight correct pronunciations and eight mispronunciations, created by changing either the onset consonant or medial vowel by a single feature, where possible (Table I). The auditory stimuli were produced in a local dialect by a native female speaker of British English in a child-directed manner and heard in the carrier phrase 'Look! Target.'

\section{Procedure}

Infants sat in a high-chair approximately $\mathrm{I} 80 \mathrm{~cm}$ away from a projection screen; eye-movements were recorded by two cameras positioned directly above the visual stimuli. Auditory stimuli were delivered via a centrally 
located speaker. The experiment was presented, coded and analyzed using the 'Look' software package (Meints \& Woodford, 2008).

Initially infants saw two training trials (hand-chair, bird-pig), always with correctly pronounced targets, to familiarize them with the procedure and improve engagement during test trials. During the test phase infants were presented with sixteen $5 \mathrm{~s}$ trials consisting of one pair of images, measuring $52 \mathrm{~cm}$ diagonally from corner to corner and $43 \mathrm{~cm}$ apart. The onset of the target word occurred at $2500 \mathrm{~ms}$, splitting the trial into pre- and post-naming phases. Between trials a smiley face was presented to re-centre infants' attention.

Throughout the experiment targets were presented equally often on the left and right of the screen. This was counterbalanced across children and the order in which trials were presented was randomized with no more than two consecutive pronunciations of the same type.

\section{Scoring}

Videos were scored to determine the infants' gaze direction and fixations on a frame-by-frame basis (every $40 \mathrm{~ms}$ ). A second skilled coder independently scored $10 \%$ of the videos with an inter-experimenter agreement Intraclass Correlation Coefficient of 0.978 (Shrout \& Fleiss, I 979).

Codings were used to calculate the amount of time infants spent looking at the target and distracter in both the pre- and post-naming phases of each trial. Only looking times that occurred between $367 \mathrm{~ms}$ and $2000 \mathrm{~ms}$ after the onset of the word were analyzed, following previous research (e.g. Swingley \& Aslin, 2000).

\section{RESULTS}

Analyses were conducted only on trials where infants looked at both images during the trial and caregivers reported the target word was known; these criteria retained $86 \%$ of all trials. We used the Proportion of Total Looks (PTL) measure, calculated as the time spent looking to the target divided by the total time spent looking at both target and distracter $(t / t+d)$. A significant increase in PTL in the post-naming phase compared to the pre-naming phase is taken as evidence that the child has recognized the word and is aware of the relationship between the target image and the target label, corresponding to a naming effect (Mani \& Plunkett, 2010; Swingley \& Aslin, 2000). Data were analyzed using a mixed-model ANOVA with the within-participant factors Naming (pre- and post-) and Pronunciation (correct and incorrect), and the between-participant factor Dialect (monodialectal and multidialectal). There was a main effect of Naming $\left(F(\mathrm{I}, 30)=\mathrm{I} \mathrm{I} \cdot 72, p=.002, \eta_{p}^{2}=.28 \mathrm{I}\right)$, an interaction between Naming and Pronunciation $\left(F(\mathrm{I}, 30)=\mathrm{I0.7} \mathrm{I}, p=.003, \eta_{p}^{2}=.263\right)$ and a significant three-way interaction between Naming, Pronunciation, and Dialect 


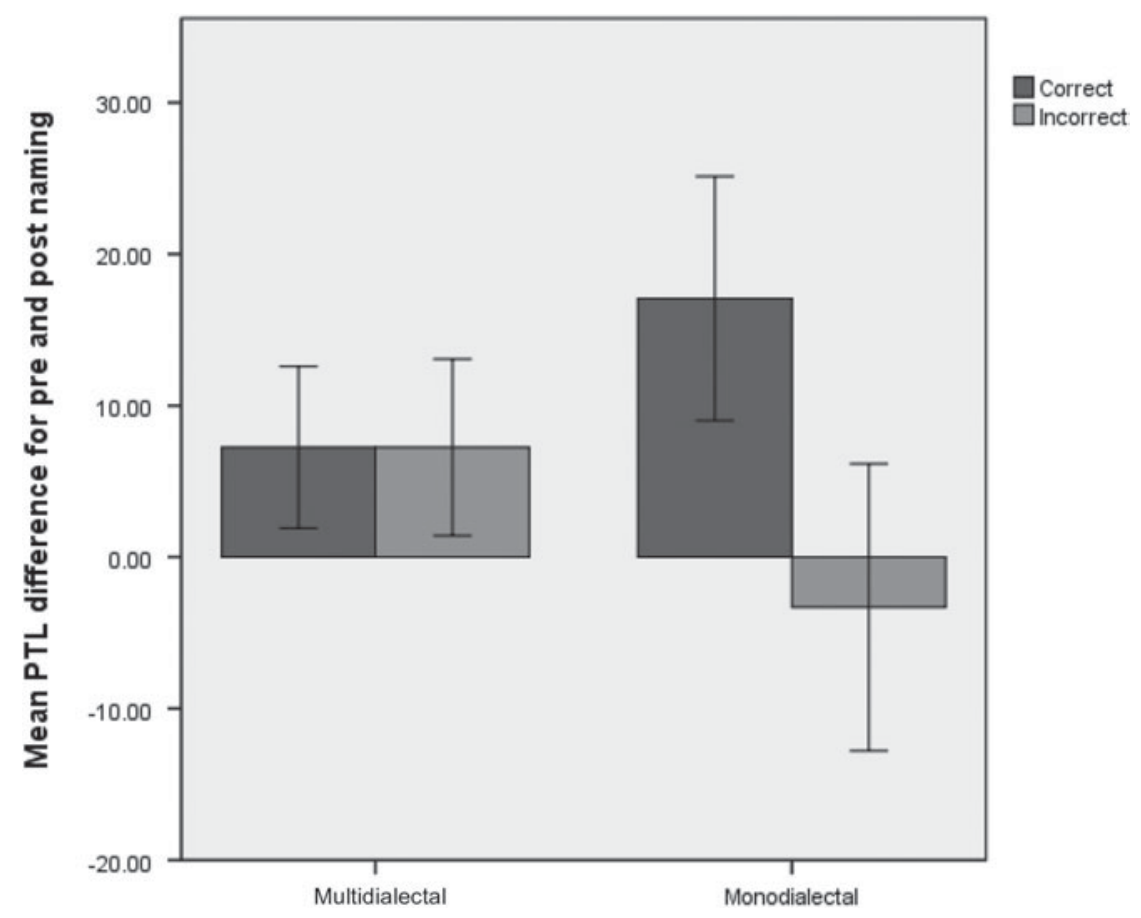

Error Bars: +/- 2 SE

Fig. I. Mean difference in the proportion of looking times to the target over the distracter (post-naming phase-pre-naming phase) for the multidialectal (left) and monodialectal (right) groups.

$\left(F(\mathrm{r}, 30)=\mathrm{I} 0.62, p=.003, \eta_{p}^{2}=.26 \mathrm{I}\right)$. Figure $\mathrm{I}$ illustrates this interaction and shows that the dialect groups are responding differently across the pronunciation types. Further exploration examines the dialect groups independently.

\section{Monodialectal infants}

In the monodialectal group a marginal main effect of Naming was found $\left(F\left(\mathrm{I}_{1} \mathrm{I}_{5}\right)=3.95, \quad p=.065, \quad \eta_{p}^{2}=.209\right)$ but no overall main effect of Pronunciation type $\left(F\left(\mathrm{I}_{1} \mathrm{I}_{5}\right)=\mathrm{I}_{\mathrm{I}} 88, \quad p=\cdot \mathrm{I}_{9}, \quad \eta_{p}^{2}=\cdot_{\left.\mathrm{I} \mathrm{I}_{2}\right) .}\right.$ A significant interaction between Naming and Pronunciation $\left(F\left(\mathrm{I}_{1} \mathrm{I}_{5}\right)=\mathrm{I} 4 . \mathrm{I} 7, p=.002\right.$, $\eta_{p}^{2}=\cdot 486$ ) was also found, indicative of the infants treating correct and incorrect pronunciations differently. Looks to the target increased from the pre-naming to the post-naming phase following correct pronunciations $\left(t\left(\mathrm{I}_{5}\right)=-4 \cdot 26, p=.00 \mathrm{I}, d=\mathrm{I}_{1} \cdot 80\right)$ but not incorrect pronunciations $\left(t\left(\mathrm{I}_{5}\right)=\right.$ $0.72, p=.48 \mathrm{I}, d=0.27)$. This supports previous work in this area showing that monolingual infants from age $\mathbf{~} ; 0$ identify a familiar target when its 
label is correctly, but not incorrectly, pronounced (e.g. Mani \& Plunkett, 2007, 2010; Swingley \& Aslin, 2000), indicating that they are sensitive to phonemic or phonetic changes in familiar words.

\section{Multidialectal infants}

In multidialectal infants, a main effect of Naming was found $\left(F\left(\mathrm{I}, \mathrm{I}_{5}\right)=\right.$ I0.1०, $\left.p=.006, \eta_{p}^{2}=\cdot 402\right)$, together with no main effect of Pronunciation $\left(F\left(\mathrm{I}, \mathrm{I}_{5}\right)=\mathrm{I}_{5} 56, p=.23 \mathrm{I}, \eta_{p}^{2}=.094\right)$ and no interaction between Naming and Pronunciation $\left(F\left(\mathrm{I}, \mathrm{I}_{5}\right)<\mathrm{I}, \eta_{p}^{2}<.00 \mathrm{I}\right)$, suggesting infants were looking longer at the target in the post-naming phase regardless of pronunciation. For correct pronunciations we found significantly longer looks to the target following naming $\left(t\left(\mathrm{I}_{5}\right)=-2 \cdot 78, p=.0 \mathrm{I}_{4}, d=0.98\right)$, as with monodialectal infants. What differed between the two dialect groups was the response when the target was incorrectly named; here we found a significant increase in PTL during the post-naming phase $(t$ ( I 5$)=-2.50 p=.024, d=0.60)$, similar to what was found for correct pronunciations.

\section{Between group comparisons}

In order to confirm that the observed differences are the result of the infants' exposure to dialects and not attributable to some other difference between groups, a series of $t$-tests were conducted. Comparisons between the dialect groups on the variables age, vocabulary scores, and socioeconomic status of caregivers measured by educational level (scored as I for postgraduate level, 2 for A-level or undergraduate degree level, and 3 for GCSEs or below) (monodialectal $M={ }_{\mathrm{I}} \cdot 38$ and multidialectal $M={ }_{\mathrm{I}} \cdot 25$ ) and occupation (scored from I to 9 based on Hollingshead, I975, with I being the lowest) (monodialectal $M=6 \cdot 44$ and multidialectal $M=6 \cdot 88$ ), revealed no significant differences between the two groups (all $p s>\cdot 05$ ). There was also no correlation between the amount of exposure to the local accent and performance in mispronounced trials $(r=.336, n=16, p=\cdot 204)$. Due to the nature of accents differing mainly on vocalic details (Wells, I982), performance on vowel and consonant mispronunciations was compared. Tests were conducted using Bonferroni adjusted alpha levels of - o 6 per test (.05/3). Results indicated that in multidialectal infants, following consonant mispronunciations there was a marginally significant increase in target looking in the post-naming phase $\left(t\right.$ I $\left.\left._{5}\right)=-2 \cdot 59, p=.020\right)$, but there was no difference in looking times following vowel mispronunciations $\left.\left(t_{(} \mathrm{I}_{4}\right)<\mathrm{I}\right)$. No differences between mispronunciation types was found for monodialectal infants (all $t \mathrm{~s}<\mathrm{I}$ ). This could suggest that multidialectal infants are more sensitive to vowel mispronunciations than consonants, or that following an initial consonant mispronunciation the remaining overlap with the correct pronunciation is enough to identify the target. 


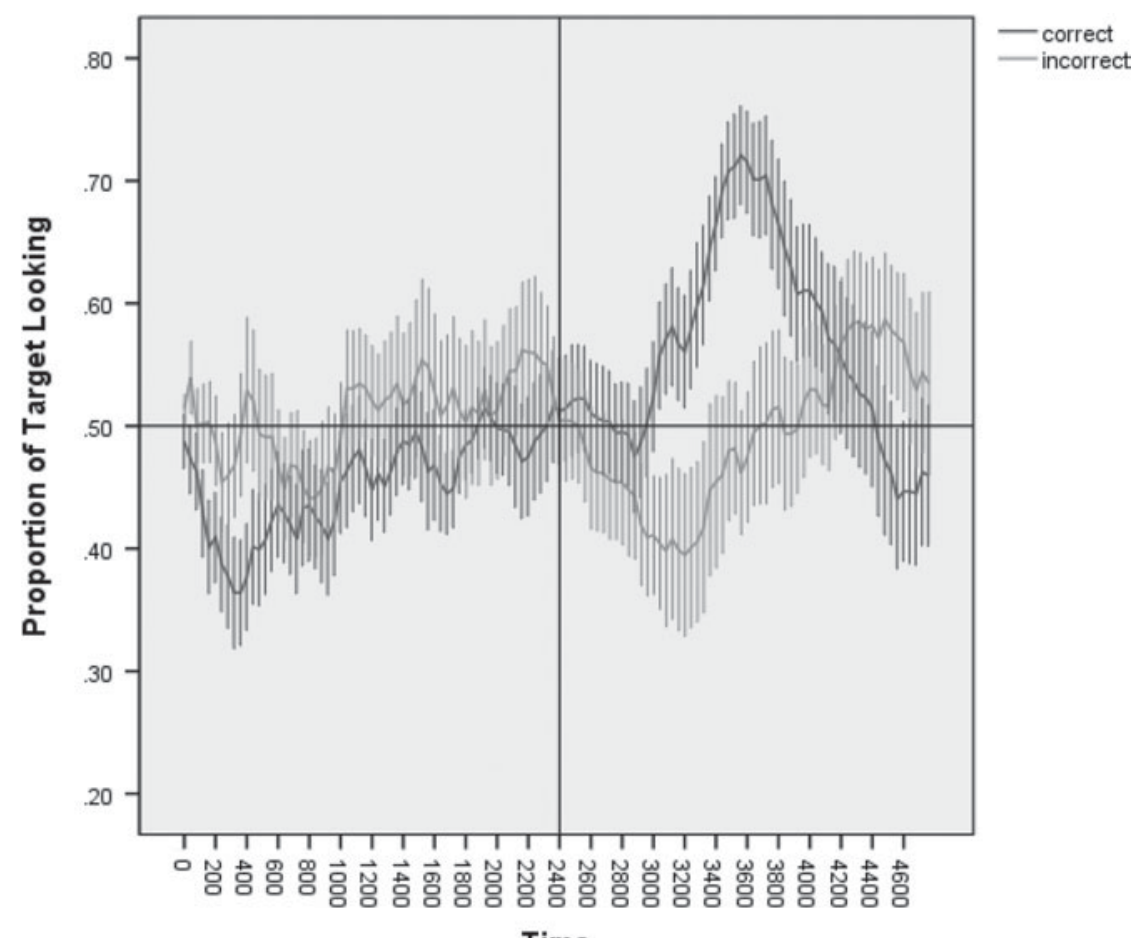

Time

Error bars: +/- $1 \mathrm{SE}$

Fig. 2. Timecourse of monodialectal infants' fixations for correct and incorrect pronunciation trials. The vertical line represents the onset of the target word.

\section{Timecourse plots}

Figures 2 and 3 plot respectively the monodialectal and the multidialectal infants' behaviour for correct and incorrect pronunciations over the course of the trial. For the monodialectal infants it is clear that looks to the target increased following correct but not incorrect pronunciations. In contrast, multidialectal infants initially look to the target in the post-naming phase but look away earlier following incorrect pronunciations, maintaining looking after correct pronunciations. This suggests that multidialectal infants take longer to disregard a mispronunciation as related to the target image.

\section{DISCUSSION}

The present study sought to add to the growing body of work looking at the effects of variability on young infants' word-learning abilities. However, in contrast with previous work, where variability is introduced during the experimental procedure, we utilized the continuous and natural variability 


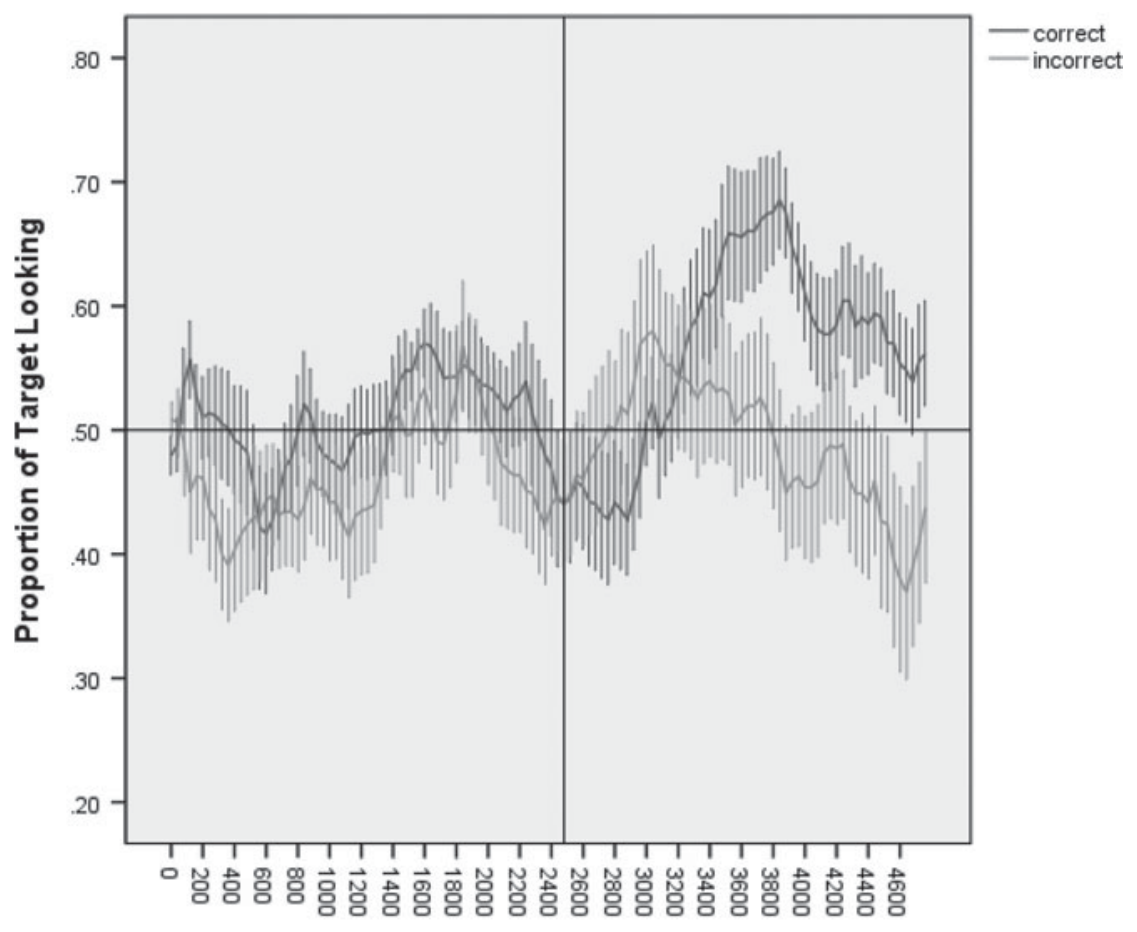

Time

Error bars: +/- $1 \mathrm{SE}$

Fig. 3. Timecourse of multidialectal infants' fixations for correct and incorrect pronunciation trials. The vertical line represents the onset of the target word.

characteristic of the input of multidialectal infants. These infants hear variable pronunciations as a result of at least one of their parents speaking with a dialect that differs from that of the local area, whereas monodialectal infants hear consistent phonological input from both parents and the ambient environment. We found that our monodialectal group of infants, who hear little input variation, behave consistently with previous findings with monolinguals (Mani \& Plunkett, 2007; Ramon-Casas, Swingley, Sebastián-Gallés \& Bosch, 2009; Swingley \& Aslin, 2000); these infants did not accept mispronunciations as adequate exemplars of familiar words, as demonstrated by a significant interaction between Naming and Pronunciation. Contrastingly, the multidialectal infants looked at the target more often after naming regardless of how the word was pronounced. The difference in performance between the two groups suggests that long-term exposure to dialectal variability does indeed have an impact on infants' representations of familiar words. 
One interpretation of these results would be to claim that they reveal a delay in the creation of detailed word representations in multidialectal infants as compared to monodialectals, similarly to the interpretation of monolingual and bilingual performance differences. According to another perspective, the pattern of results could indicate that multidialectals are more able than monodialectals to accommodate variations in speech, due to more relaxed phonetic boundaries. In what follows we discuss both of these interpretations.

The first explanation is that phonological specificity of early lexical representations is affected by variable input, as suggested by results from Best et al. (2009) and Rost and McMurray (2010). Monodialectal infants' lexical entries contain sufficient phonological detail that mispronunciations of a single phoneme interfere with the identification of a target referent as has been shown as early as age i; (Mani \& Plunkett, 20ı0). That multidialectal infants behave differently suggests that their representations may be phonologically less well specified as a result of exposure to dialectally variable pronunciations. The development of representations that are robust enough to deal with phonological deviations in the form of mispronunciations may be hindered by inconsistencies in the pronunciations they are hearing as a result of dialectal variation.

A second interpretation of these results could relate to the broadening of phonetic categories suggested by studies such as White and Aslin (20 I I). White and Aslin propose that infants accept the trained vowel-shifted pronunciation due to a relaxation of a particular vowel boundary encountered in training; that is an input-specific boundary relaxation. Although the current results differ from those found by White and Aslin (20II), where infants were able to detect mispronunciations that differed from the vowel shift they experienced, boundary relaxation could still be a factor here. In the current study multidialectal infants treat mispronunciations similarly to correct pronunciations, despite the fact that they have not encountered them previously nor had any experience with the changes tested (more specifically, the changes were phonemically valid in their dialects, but did not correspond to any current dialect variations). Perhaps long-term exposure to variability results in a more general relaxation of boundaries, rather than an input-specific relaxation, which then leads to less well specified representations of individual words in their lexicon.

Similarly, Schmale et al. (20 I I) found that even relatively brief exposure to variable pronunciations relaxes phonetic boundaries in a more general way to accommodate variation, and the results presented here indeed seem to suggest a similar effect. One key difference between Schmale et al., and the current paper is the duration of exposure to variability. For the infants in the Schmale et al., paper the variability is brief and heard only during the study, whereas the infants in this paper hear continuously variable pronunciations. It would be of interest to further explore the effects 
of exposure duration in relation to any lasting effects of broadened categories. That is, the effects observed by Schmale et al., could be short-lived whereas long-term exposure to variability could result in persistent boundary broadening. This could be problematic for infants learning new words as there are likely to be instances where natural dialect variation crosses phonetic boundaries. This could lead infants to consider two words pronounced differently as the same word when actually they are minimal pair words, e.g. cot and cat. The reverse could also be expected: an accented word could be considered a different word and not related to the target.

Returning to the parallel between multilingual and multidialectal children, Ramon-Casas and Bosch (2010) suggest that cognate words are less well represented in the lexicon of the bilingual child. Indeed Ramon-Casas et al. (2009) found that Spanish-Catalan bilingual infants failed to discriminate a Catalan-specific contrast $(/ \mathrm{e} /$ and $/ \varepsilon /)$ when tested with familiar cognate words ([ga'letə] to [gə'let ə] 'cookie'). However, the same contrast in non-cognate words ([pi'tet] 'bib' to [bu'let 'mushroom') was successfully discriminated (Ramon-Casas \& Bosch, 2010). As mentioned previously, for multidialectal infants nearly all words are cognates: often they hear two pronunciations of each word due to the dialect differences they are exposed to. Cognate effects could be affecting the representations of multidialectal infants in much the same way as they are problematic for bilingual infants, leading to them having less well represented lexical entries.

Additionally, Floccia, Delle Luche, Durrant, Butler \& Goslin (2012) found in an IPL task that multidialectal infants aged $\mathrm{I} ; 8$ exposed to both versions of a specific English accent feature, rhoticity, recognize only rhotic pronunciations (spoken in the community) and not non-rhotic pronunciations (spoken at home), despite more frequent exposure to the non-rhotic versions. Specifically, infants heard words that could be produced rhotically such as car, in either a rhotic or non-rhotic pronunciation. All infants, mono- or multidialectal, looked longer at the target pictures than the distracter pictures when the corresponding words were produced in the rhotic version, but not when they were non-rhotically produced. This was interpreted as evidence that infants exposed to multiple variants of words encode only a single form as the canonical representation and then fail to recognize non-canonical variants. This is problematic for a cognate-based explanation of the current results; the infants in Floccia et al. (2012) were exposed to both forms of the target words from their earliest age, placing them in the same category as the multidialectal infants in the present study. If the cognate explanation were to hold, multidialectal infants should identify both forms, rhotic and non-rhotic. However, the words included in the current study have no specific contrasting feature, such as rhoticity, so here we are tapping into a more general lack of specificity of infants' representations than one related 
specifically to shared cognates, supporting the proposal that multidialectal input results in relaxed and broadened phonetic categories.

A further, task-demand based, explanation could be that the greater phonological overlap between the spoken target and the intended target image than between the spoken target and the distracter image is leading multidialectal infants to use a 'best fit' strategy for target recognition and distracter exclusion. That is, the lack of phonological overlap between gat and cow allows them to reject the distracter cow, but the shared phonological content of gat and cat causes them to look longer at the picture of the 'cat', ignoring the elements of the word that are mismatched. This would, in fact, be a sensible strategy for multidialectal infants to adopt, given the variability of the phonological information they hear. In this way they focus on those elements of the words and images that are complementary and use these to guide their looking behaviour.

The key finding of the current study is that multidialectal infants process mispronunciations of familiar words differently to their monodialectal peers, showing for the first time that long-term exposure to within-language variation affects the specificity of early representations of words. Further work into this area is needed to identify whether multidialectal infants' representations are ever specified enough that they are able to identify mispronunciations in the same ways as their monodialectal counterparts or whether the effects observed here are permanent.

\section{REFERENCES}

Albareda-Castellot, B., Pons, F. \& Sebastián-Gallés, N. (20I I). The acquisition of phonetic categories in bilingual infants: new data from an anticipatory eye movement paradigm. Developmental Science I4(2), 395-401.

Altendorf, U. \& Watt, D. (2004). The dialects in the South of England: phonology. Handbook of Varieties of English $\mathbf{1}, \mathrm{I}_{7} 8-2 \mathrm{O} 3$.

Best, C. T., Tyler, M. D., Gooding, T. N., Orlando, C. B. \& Quann, C. A. (2009). Development of phonological constancy: toddlers' perception of native- and Jamaican-accented words. Psychological Science 2o(5), 539-42.

Bialystok, E., Luk, G., Peets, K. F. \& Yang, S. (2010). Receptive vocabulary differences in monolingual and bilingual children. Bilingualism: Language and Cognition $\mathbf{1 3}(4), 525-3 \mathrm{I}$.

Bosch, L. \& Sebastián-Gallés, N. (2003). Simultaneous bilingualism and the perception of a language-specific vowel contrast in the first year of life. Language and Speech 46(2/3), 2 I 7-43.

Cattani, A., Abbot-Smith, K., Farag, R., Krott, A., Arreckx, F., Dennis, I. \& Floccia, C. (in press). How much exposure to English is necessary for a bilingual toddler to perform like a monolingual peer in language tests? International Fournal of Language and Communication Disorders.

Fennell, C. T., Byers-Heinlein, K. \& Werker, J. F. (2007). Using speech sounds to guide word learning: the case of bilingual infants. Child Development 78(5), i 5 1 $0-25$.

Floccia, C., Delle Luche, C., Durrant, S., Butler, J. \& Goslin, J. (2012). Parent or community: Where do 20-month-olds exposed to two accents acquire their representation of words? Cognition 124, 95-100. 
Hamilton, A., Plunkett, K. \& Schafer, G. (2000). Infant vocabulary development assessed with a British Communicative Development Inventory. Fournal of Child Language 27(3), $689-705$.

Hughes, A. \& Trudgill, P. (1996). English accents and dialects: an introduction to social and regional varieties of English in the British Isles (3rd ed.). London: Arnold.

Mani, N. \& Plunkett, K. (2007). Fourteen-month-olds pay attention to vowels in novel words. Developmental Science II (I), 53-9.

Mani, N. \& Plunkett, K. (2010). Twelve-month-olds know their cups from their keps and tups. Infancy I5(5), 445-70.

Meints, K. \& Woodford, A. (2008). Lincoln Infant Lab Package 2008: a new programme package for IPL, preferential listening, habituation and eyetracking [www document: Computer software \& manual]. Online: <http://www.lincoln.ac.uk/psychology/babylab. htm>.

Pearson, B. Z., Fernández, S. C., Lewedeg, V. \& Oller, D. K. (r997). The relation of input factors to lexical learning by bilingual infants. Applied Psycholinguistics r8, 4I-58.

Pearson, B.Z., Fernández, S. C. \& Oller, D. K. (I993). Lexical development in bilingual infants and toddlers: comparison to monolingual norms. Language Learning 43(I), 93-I 20.

Poulin-Dubois, D., Bialystok, E., Blaye, A., Polonia, A. \& Yott, J. (2013). Lexical access and vocabulary development in very young bilinguals. International Fournal of Bilingualism I7 ( I ), 57-70.

Ramon-Casas, M. \& Bosch, L. (2010). Are non-cognate words phonologically better specified than cognates in the early lexicon of bilingual children? In M. Ortega-Llebaria (ed.), Selected proceedings of the $4^{\text {th }}$ Conference on Laboratory Approaches to Spanish Phonology, 3 $\mathrm{I}-6$. Somerville, MA: Cascadilla.

Ramon-Casas, M., Swingley, D., Sebastián-Gallés, N. \& Bosch, L. (2009). Vowel categorization during word recognition in bilingual toddlers. Cognitive Psychology 59(I), 96-I I I.

Rost, G. C. \& McMurray, B. (2009). Speaker variability augments phonological processing in early word learning. Developmental Science I2(2), 339-49.

Rost, G.C. \& McMurray, B. (2010). Finding the signal by adding noise: the role of noncontrastive phonetic variability in early word learning. Infancy $\mathbf{5}$ (6), 608-35.

Schmale, R., Cristia, A., Seidl, A. \& Johnson, E. K. (2010). Developmental changes in infants' ability to cope with dialect variation in word recognition. Infancy $\mathbf{5} 5(6), 650-62$.

Schmale, R., Hollich, G. \& Seidl, A. (201 I). Contending with foreign accent in early word learning. Fournal of Child Language 38(05), r o96-г 08.

Shrout, P. E. \& Fleiss, J. L. (I 979). Intraclass correlations: uses in assessing rater reliability. Psychological Bulletin 86(2), 420-28.

Swingley, D. \& Aslin, R. N. (2000). Spoken word recognition and lexical representation in very young children. Cognition 76(2), I 47-66.

Trudgill, P. (1999). The dialects of England (2nd ed.). Oxford: Blackwell.

Weinberger, S. H. (2003). Speech accent archive. George Mason University. Online: <http:// accent.gmu.edu>.

Werker, J. F., Cohen, L. B., Lloyd, V. L., Casasola, M. \& Stager, C. L. ( 1998). Acquisition of word-object associations by I 4-month-old infants. Developmental Psychology 34, I 289-309.

White, K. S. \& Aslin, R. N. (20I I). Adaptation to novel accents by toddlers. Developmental Science I4(2), 372-84. 


\section{APPENDIX A}

Below is the passage parents were asked to read, the parent who attended with their child was recorded on the day and the other parent (most commonly the father) was called and recorded over the telephone. This passage is used as it contains most of the sounds of English and is made up of common English words that use a range of difficult sounds and sound sequences (Weinberger, 2003).

Please call Stella. Ask her to bring these things with her from the store: Six spoons of fresh snow peas, five thick slabs of blue cheese, and maybe a snack for her brother Bob. We also need a small plastic snake and a big toy frog for the kids. She can scoop these things into three red bags, and we will go meet her Wednesday at the train station. 


\section{APPENDIX B}

List of the most common differences between the dialects spoken by the parents of multidialectal infants and the local South West accent. Shaded boxes indicate where the phoneme is realized differently from the South West for that dialect (adapted from Hughes and Trudgill, r 996).

\begin{tabular}{|c|c|c|c|c|c|c|c|c|c|}
\hline Dialect & $\begin{array}{l}/ \Lambda / \\
\text { (in } m u d)\end{array}$ & $\begin{array}{l}\text { /æ/ } \\
\text { (in path) }\end{array}$ & $\begin{array}{l}\text { /a/: } \\
\text { (in palm) }\end{array}$ & $\begin{array}{l}\text { /i:/ } \\
\text { (in } h a z y)\end{array}$ & $\begin{array}{l}/ \mathrm{r} / \\
\text { (in bar) }\end{array}$ & $\begin{array}{l}/ \mathrm{g} / \\
\text { (in sing) }\end{array}$ & $\begin{array}{l}/ \mathrm{j} / \\
(\text { in } f e w)\end{array}$ & $\begin{array}{l}\text { [ei] } \\
\text { (in gate) }\end{array}$ & $\begin{array}{l}{[x]} \\
\text { (in farmer) }\end{array}$ \\
\hline North East (Yorkshire) & 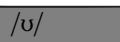 & & $|æ|$ & & $\overline{[c]}$ & & & {$[\mathrm{e}:]$} & Absent \\
\hline Merseyside (Liverpool) & $\mid \mathrm{v} /$ & & $/ \mathfrak{/ x} /$ & & {$[\mathrm{c}]$} & $/ \mathrm{hg} /$ & & & \\
\hline East Midlands (Leicester) & $\mid \mathrm{v} /$ & & $|æ|$ & 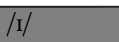 & Absent & & Dropped & & Absent \\
\hline $\begin{array}{l}\text { West Midlands } \\
\text { (Birmingham, Staffordshire) }\end{array}$ & $|\mathrm{v}|$ & & $|æ|$ & & Absent & $\operatorname{lng} /$ & & & Absent \\
\hline Wales & & & $|æ|$ & & Absent & & & $\overline{[\mathrm{e}:]}$ & Absent \\
\hline South Midlands (Northampton) & & $/ \mathrm{a} /:$ & $|æ|$ & & Absent & & Dropped & & Absent \\
\hline $\begin{array}{l}\text { South East (London, Buckinghamshire, } \\
\text { Hampshire, Reading) }\end{array}$ & & /a/: & $\mid \mathfrak{| x |}$ & & Absent & & & & Absent \\
\hline
\end{tabular}




\section{APPENDIX C}

List of dialects heard by each of the multidialectal infants included in the study. Both parents of monodialectal infants spoke with a British South West dialect. Infants 14 and I 5 heard the local dialect only from their childcare provider. However, the behaviour of these infants followed the same pattern as the others in the multidialectal group. These two infants were still familiar with the local pronunciations of words hearing the local dialect 35 and $26 \%$ of the time respectively.

\begin{tabular}{rllc}
\hline & \multicolumn{2}{c}{ Multidialectal } & \\
\cline { 2 - 3 } Child & \multicolumn{1}{c}{ Mother } & \multicolumn{1}{c}{ Father } & $\begin{array}{c}\text { \% exposure to } \\
\text { South West }\end{array}$ \\
\hline I & South West & Midlands & 53 \\
2 & South West & London & 57 \\
3 & South West & Coventry & 5 I \\
4 & South East & South West & 52 \\
5 & South West & Liverpool & 62 \\
6 & South West & Yorkshire & 3 I \\
7 & South West & Birmingham & 53 \\
8 & South West & Buckinghamshire & 33 \\
9 & South West & Liverpool & 65 \\
I0 & South West & Hampshire & 44 \\
I I & South West & Yorkshire & 3 I \\
I2 & South West & London & 33 \\
I3 & Staffordshire & South West & 46 \\
I4 & Wales & Reading & 35 \\
I5 & Leicester & Leicester & 26 \\
I6 & Northampton & South West & 33 \\
\hline
\end{tabular}




\section{APPENDIX D}

Example of the questions asked to multidialectal infants. All parents were asked about the amount of time infants spent sleeping and with a childcare provider, including details of dialects heard whilst there, with the additional questions below asked to the parents of multidialectal infants.

\begin{tabular}{|c|c|}
\hline I & Can you please tell us the additional accent (e.g. Manchester)? \\
\hline 2 & Which parent speaks with this accent? \\
\hline 3 & $\begin{array}{l}\text { In an average week how many hours does your child spend with a } \\
\text { local accent speaking childcare provider (nursery, childminder, } \\
\text { relative, friend)? If your childcare provider speaks with a non-local } \\
\text { accent please add details below of time spent there and the accent. }\end{array}$ \\
\hline 4 & $\begin{array}{l}\text { Over a } 24 \text { hour period, how many hours will your child spend } \\
\text { sleeping? (include nap times and overnight) }\end{array}$ \\
\hline 5 & When both parents are present who speaks more to your child? \\
\hline a & The additional accent speaking parent \\
\hline b & The local accent speaking parent \\
\hline $\mathrm{c}$ & We both speak equal amounts \\
\hline 6 & $\begin{array}{l}\text { Are there times in a typical week when your child is with just one } \\
\text { parent (e.g. always cared for by Dad on Saturdays or Mum on } \\
\text { Sundays)? }\end{array}$ \\
\hline a & $\begin{array}{l}\text { How many hours in an average week with just the additional accent } \\
\text { speaking parent? }\end{array}$ \\
\hline b & $\begin{array}{l}\text { How many hours in an average week with just the local accent } \\
\text { speaking parent? }\end{array}$ \\
\hline
\end{tabular}

